\title{
El concepto de "fraternidad" como valor democrático en la política mexicana
}

\author{
The concept of "fraternity" as a democratic value in mexican politics
}

DOI: https://doi.org/10.21803/penamer.14.27.455

Joaquín Ordóñez

https://orcid.org/0000-0002-6447-7188.

¿Cómo citar este artículo?

Ordoñez, J. (2021). El concepto de "fraternidad" como valor democrático en la política mexicana. Pensamiento Americano, 14(27), 39-56.

DOI: https://doi.org/10.21803/penamer.14.27.455

\section{Resumo}

Introducción: se pretende demostrar que la fraternidad como valor democrático y como concepto que debe ser aplicado a la realidad mexicana no lo es así. Objetivo: evidenciar que, al no aplicarse cabalmente la fraternidad, los otros dos valores de la democracia (libertad e igualdad) se perjudican en detrimento de la democracia mexicana como forma de gobierno. Materiales y método: análisis en el contexto político nacional, partiendo de la ineficaz actuación de las autoridades estatales que ha provocado descontento social y desconfianza ciudadana y se parte del análisis conceptual de los valores mencionados como unidades del discurso tanto teórico como jurídico. Resultados y conclusiones: a pesar de que la fraternidad no está expresamente codificada en la ley, los conceptos de libertad, igualdad, respeto, dignidad, interés general, la no discriminación, solidaridad, derechos humanos, etc., la refieren directamente, además de que puede tener más importancia que la libertad y la igualdad y de que los aspectos ético y moral pueden ser la base para considerar al otro y así evitar el individualismo, la ambición y el egoísmo derivados, generalmente, de políticas capitalistas.

Keywords: Fraternidad; Democracia; Política; Valores democráticos; Estado democrático.

\section{Resumen}

Introduction: it is intended to demonstrate that fraternity as a democratic value and as a concept that should be applied to Mexican reality is not so. Objective: to show that, by not applying fraternity fully, the other two values of democracy (freedom and equality) are harmed to the detriment of Mexican democracy as a form of government. Materials and method: analysis in the national political context, starting from the ineffective action of the state authorities that has caused social discontent and citizen distrust and is based on the conceptual analysis of the values mentioned as units of both theoretical and legal discourse. Results and conclusions: although fraternity is not expressly codified in law, the concepts of freedom, equality, respect, dignity, general interest, non-discrimination, solidarity, human rights, etc., refer to it directly, in addition to the fact that it may have more importance than freedom and equality and 
that ethical and moral aspects may be the basis for considering the other and thus avoid individualism, ambition and selfishness derived, generally, from capitalist policies.

Palabras Clave: Fraternita; Democracy; Politics; Democratic values; Democratic state.

\section{Abstract}

$x x$

Keywords: aa

\section{Perfiles} del Estado de México. Correo electrónico institucional: jordonezs@uaemex.mx. 


\section{Introducción}

En un Estado que por mandato de su Constitución y por regulación de sus leyes internas debe tener una forma de gobierno democrática, debe también, en consecuencia, poseer las características que son inherentes a la democracia, lo cual incluye sus principios (como la tolerancia y la pluralidad) y valores (como la libertad, la igualdad y la fraternidad), de tal manera que en su estructura estatal deben estar presentes esas características que no solamente deben ser tomadas en cuenta desde el punto de vista teórico o conceptual, sino también en la realidad política, ya que de nada o de poco sirve que un Estado se estructure y se organice con esa forma de gobierno desde su expresión en la legislación si en los hechos no se cumple a cabalidad con los mismos. La democracia como concepto no debe ser una idea distante o distanciada de los hechos concretos, sino que debe fungir como una verdadera regla de la forma de gobierno y también de la conducta política en un Estado. Sin embargo, la ineficaz actuación de la estructura gubernamental ha provocado el descontento social y el hartazgo ciudadano, por ejemplo, en cuanto a seguridad pública el Estado mexicano no ha logrado cumplir su objetivo de proporcionar a sus habitantes, lo anterior considerando las tasas de incidencia delictiva de ocurrencia (número de eventos individuales de victimización delictiva reportados por cada cien mil habitantes) que han ido en aumento: a) año 2010/1, 30535 eventos; b) año 2011/2, 29200 eventos; c) año 2012/3,35139 eventos; d) año 2013/4, 41563 eventos; e) año 2014, 41655 eventos; y f) año 2015, 35497 eventos (INEGI, 2017). Otro ejemplo lo constituye las agresiones a periodistas que transgreden y violentan derechos humanos: en el sexenio de Felipe Calderón 1092 agresiones contra la prensa, 48 asesinatos a periodistas y 15 desapariciones de periodistas; en el sexenio de Enrique Peña 1502 agresiones contra la prensa, 47 asesinatos a periodistas y 4 desapariciones de periodistas (Article 19, 2018). De acuerdo con algunos medios de información

...el despliegue de más elementos de la Guardia
Nacional por todo el país no se traducirá en la disminución de la criminalidad (...) la pacificación en México se ve lejos, y muestra de ello es que en los últimos tres meses se registraron 11,373 homicidios. En los primeros ocho meses del gobierno de Andrés Manuel López Obrador suman ya 30,137 asesinatos (...) si bien hay más de 50,000 elementos de la Guardia Nacional en tareas de seguridad, este nuevo cuerpo sigue sin existir, porque en los hechos operan de la misma forma que lo hicieron los últimos años. (Arista, 2019)

Algunos organismos internacionales han catalogado la situación en México como muy grave, incluso posicionándolo en el nivel de "guerra", solamente similar a países como Afganistán, Siria, Libia, Yemen, Egipto y Turquía (HIIK, 2019). Lo anterior solamente como ejemplo, sin mencionar otros hechos de relevancia que también han ocurrido en México, como los casos de Ayotzinapa, San Mateo Atenco y Ciudad Juárez. Todo ello provoca que se ponga en duda la verdadera aplicación y observación de los valores y principios de la democracia, especialmente el de la fraternidad, ya que esta significa amistad, afecto, respeto, justicia, dignidad, unión de voluntades, correspondencia, alianza entre personas, lo cual la hace ser un valor universal aplicable en toda sociedad que se jacte de ser democrática. Sin embargo, con todos esos conflictos que se presentan en las realidad política y social de México en los últimos años, se pone en duda, primero, la conceptualización de la democracia con esos valores incluidos y, segundo, la verdadera aplicación de la fraternidad como un elemento democrático que debería estar presente por mandato constitucional.

Si la fraternidad es uno de los valores de la democracia, luego entonces se debe considerar también como una de sus características, lo cual significa que en todo Estado que formalmente se jacte de ser democrático debe estar incluida esa cualidad no solamente desde le punto de vista formal, sino también en cuanto a la realidad social, ya que 
la fraternidad como característica de la democracia debería estar presente en todo el actuar de todas las personas, máxime en el de aquellas que están directamente relacionadas con la política y con la función pública. La fraternidad debe estar incluida no solamente desde el punto de vista formal, lo cual ya sería de entrada una congruencia entre lo que se establece en normas de superior jerarquía con otras de menor jerarquía o reglamentarias, dentro de un sistema jurídico, sino también desde su aplicación efectiva en la realidad social. Lo anterior significa que, además de la formalidad y de la congruencia de las normas jurídicas en un sistema normativo, debe haber congruencia con los actos concretos emanados de la aplicación de las cualidades formalmente previstas. Uno de los fundamentos más importantes para lo anterior es que la fraternidad implica un deber moral de autoprotección, pero también de protección a los demás integrantes de la comunidad, de la sociedad o del Estado en el que se encuentren inmersos.

\section{LOS VALORES DEMOCRÁTICOS}

Los valores democráticos no pueden ser solamente abordados desde la perspectiva de la teoría que sustenta a la democracia, ya que se trata de conceptos de carácter filosófico que atienden más a los aspectos axiomáticos de la democracia, misma que no debe ser revisada solamente desde la perspectiva de forma de gobierno pues permea en muchas aristas de la vida social y de la política. Se trata de adoptar una posición conceptual desde la que se debe analizar la idea de "fraternidad" como valor democrático, es decir, se deberá adoptar un eje desde el cual poder partir hacia la reflexión de esa fraternidad en el contexto de la actuación política en México. La axiología, como rama de la filosofía, nos permite conocer las pautas analíticas de los valores, ya que está centrada precisamente en el estudio de su naturaleza y características, así como las diversas teorías que constituyen su estudio (González, 2005, p. 279). Las personas consideramos como "valioso" algo que es bueno para alguien o para todos, el valor que tienen las cosas es la cualidad subjetiva que le damos las personas a algo o a una acción. Así decimos que este o aquel objeto es valioso o que tal o cual conducta es valiosa, en la medida en la que son buenos o justos para uno mismo o para las demás personas. Por eso los valores son cualidades que refieren a sujetos pensantes $\mathrm{y}$ racionales capaces de emitir un juicio acerca de lo que le rodea y también refiere a los objetos que circundan en la realidad social, tales como cosas o acciones. Como consecuencia de la calificación que el sujeto realiza sobre un objeto surge una graduación del valor, misma que depende de las circunstancias temporales y espaciales en las que se "valora" tal o cual objeto u acción, de tal manera que las conductas (así como las cosas) ocurridas en la realidad social pueden tener un mayor o menor "valor" dependiendo de la cantidad de beneficio o de justicia que proporciona a las personas o a la sociedad. Cuanto más se acerque una cosa o una acción a ese ideal de beneficio o de justicia, mayor será su “valor”, de tal manera que algo con más valor es más apreciado por la comunidad y, por ende, ese algo debe ser procurado y protegido.

Ese es uno de los motivos por los que la legislación y el derecho en general se basan en los valores, ya que lo jurídico tiene como finalidad general regular la vida de las personas en sociedad para que puedan lograr sus objetivos y metas personales y comunitarias. De ahí que la legislación, como una de las manifestaciones del derecho, tenga como base los valores que han sido aceptados y reconocidos universalmente con la finalidad de que la sociedad tenga parámetros mínimos de convivencia y desarrollo. Por ello, la normatividad jurídica tiene (o al menos debe tener) una base axiomática que le da sustento y razón de ser para que así pueda ser aplicada legítimamente y para que la sociedad reciba el beneficio de las situaciones y acciones sociales y políticas dotadas de valor. En este sentido, en cuanto serefierealatemáticaabordadaenelpresentetrabajo, la democracia como forma de gobierno estipulada en los documentos jurídicos tanto fundamentales como reglamentarios, es también un aspecto de la vida política y social que debe ser soportado por los valores, máxime cuando forma parte del entramado

Pensamiento Americano Vol. 14 - No. 27 - p.p. 39-56 • 2021 • Enero - Junio • Corporación Universitaria Americana • Barranquilla, Colombia • ISSN-e: 2745-1402 http://publicaciones.americana.edu.co/index.php/pensamientoamericano/index 
sistema jurídico de un Estado constitucional y democrático. Los lineamientos reguladores de un Estado y de un gobierno, tanto en su forma como en su estructura y funcionamiento, también tienen su base en el derecho y en la legislación que de ahí se desprende, los cuales a su vez tienen su base en los valores, de tal manera que también la forma de gobierno democrática (y la codificación jurídica que la fundamenta) tiene un sustento axiológico. La democracia es una forma de gobierno que cuenta con diversas características y cualidades que la hacen un sistema político y social deseable y aplicable en las sociedades contemporáneas, las cuales son, entre otras: soberanía, mayoría, pluralismo, tolerancia, etc., identificadas como principios democráticos, pero también otros que por su importancia son considerados como valores: libertad, igualdad y fraternidad, siendo esta última la que interesa para el presente trabajo.

La "fraternidad", en una de sus acepciones más básicas, significa "hermandad", es decir, que en un medio en el que se considerada a la fraternidad como uno de los valores (y, por consecuencia, característica) de las relaciones políticas y sociales, el trato debe ser similar al trato que se produce entre personas que tienen parentesco de hermanos, y con este parámetro (que parece ser simple) se deben producir acciones diferentes, los sujetos que estén inmersos en ese ideal deberán dirigir sus conductas a cumplir con los objetivos de una relación de hermanos, en la que las intenciones morales son, mínimamente, de respeto y de ayuda, lo cual significa enfatizar los valores (no los antivalores): "Afirmar el valor de la fraternidad, es decir, afirmar que todos los seres humanos deben tratarse como hermanos significa, en primer lugar, enfatizar los valores (...) de la libertad e igualdad de los ciudadanos..." (Salazar y Woldenberg, 2012, pp. 32-33), pero no debemos olvidar los otros principios (o características) de la democracia, como el de la pluralidad, que implica la existencia de una multiplicidad de posturas, pensamientos, ideologías, etc., todas ellas conviviendo en un mismo medio democrático con la única limitante de no lesionar derechos de terceros, tales diferencias deben ser respetadas (e incluso promovidas) en una democracia, pero eso no significa que las conductas regidas por la fraternidad (que incluye a la pluralidad y sus diversos efectos) deban ser similares al trato que un enemigo merece: "Pero significa algo más (...) que a pesar de sus diferencias y conflictos de intereses o de opinión, los miembros de una sociedad no deben verse como enemigos, es decir, como divididos en bandos contrapuestos e irreconciliables, sino, en todo caso, como copartícipes parcialmente conflictivos en la formación de la voluntad política nacional...” (Salazar y Woldenberg, 2012, pp. 32-33).

Ahora bien, también la conceptualización de la democracia y de sus valores democráticos incluidos requiere ser considerada comoun sistema conceptual, pero, más que eso, como un entramado axiológico que obliga a visualizar a la fraternidad no como un concepto o idea aislado, sino como parte de otras categorías pertenecientes al género "democracia" y que, por lo mismo, comparten determinadas connotaciones conceptuales, de tal manera que no se debe abordar el estudio de la fraternidad sin antes considerar a los otros dos valores que comparten su posición axiomática. Históricamente, el lema "Libertad, igualdad y fraternidad" fue acuñado durante la revolución francesa y, aunque en un inicio no tuvo la repercusión esperada, gradualmente fue adquiriendo vigencia y uso:

Herencia del siglo de las Luces, la divisa "Libertad, Igualdad, Fraternidad" se proclama por vez primera durante la Revolución francesa. Cuestionada a menudo, acaba por imponerse bajo la III República. Está consignada en la Constitución de 1958 y hoy día forma parte de nuestro patrimonio nacional... (France Diplomatie, s/f).

Hasta que finalmente cada uno de sus tres conceptos fueron aceptados como características axiológicas de la democracia:

De los tres principios de la Revolución Francesa 
-libertad, igualdad, fraternidad-, no sólo es el de fraternidad el menos estudiado y el más abandonado, sino también el más enigmático, filosóficamente hablando (...) no sólo ha tenido un destino histórico-real accidentado, sino que la propia noción, el significado y el alcance de la misma resultan prima facie vagarosos. (Domènech, 2013, p. 15)

La "libertad", de acuerdo con el diccionario de la lengua, es aquella facultad natural que tiene el hombre de obrar de una manera o de otra, y de no obrar, por lo que se le considera responsable de sus actos, también es un estado o noción de quien no es esclavo o de quien no está preso o un derecho de valor superior que asegura la libre determinación de las personas, es asimismo, una prerrogativa, privilegio o licencia y lo considera como aquella condición de las personas no obligadas por su estado al cumplimiento de ciertos deberes (RAE, 2019). Respecto a la "igualdad", el mismo diccionario establece que es la conformidad de algo con otra cosa en naturaleza, forma, calidad o cantidad, es la correspondencia y proporción que resulta de muchas partes que uniformemente componen un todo y es también un principio que reconoce la equiparación de todos los ciudadanos en derechos y obligaciones (RAE, 2019). De ahí que la igualdad sea un valor para la democracia, para los estados democráticos $\mathrm{y}$, en general, para todo aquello que se presente o se califique como democrático, sobre todo porque tiene implícitos ciertos conceptos e ideales de carácter jurídico que son equiparables con la equidad y con la justicia, de tal manera que las democracias modernas (y también las incipientes) han incluido en su catálogo de derechos y de prerrogativas a la igualdad, relacionándola con la forma de gobierno e incluyendo tal concepto como un ideal en la codificación jurídico-normativa, tanto en los documentos fundamentales (Constitución) como en los secundarios o reglamentarios (legislación federal y local).

En conjunto, los valores democráticos (libertad, igualdad y fraternidad) tienden hacia un objetivo moral y jurídico de mayor envergadura: la justicia.
En efecto, las aspiraciones y deseos que las personas tienen acerca del bienestar, del desarrollo, de la seguridad, etc., pueden ser logradas gracias a la práctica de la justicia, no solamente en el ámbito jurisdiccional, sino también en el más básico de la convivencia cotidiana de los seres humanos, con lo que se pueden establecer las condiciones necesarias para que en la conducta individual y en las acciones generales de la sociedad se puedan incluir los efectos de la justicia, todo ello con auspicio de un orden jurídico y social adecuado. Por ello, también la justicia es uno de los valores de la democracia que debe ser incluida junto con la libertad, la igualdad y la fraternidad, ya que ese concepto alude a un principio de Derecho que consiste en dar a cada quien lo que le corresponde, lo cual es claro que tiene una estrecha relación y una gran congruencia con esos otros tres valores de la democracia (el de fraternidad incluido, desde luego) y también es claro que en un Estado democrático el legislador -y el constituyente- debe producir las normas jurídicas con un contenido acorde con esos valores e, incluso, como un eje rector del contenido de las leyes, como un axioma de las mismas, para que la sociedad y todo aquel destinatario de la norma jurídica sea parte del vínculo necesario entre la libertad e igualdad, pero también entre la fraternidad y, en consecuencia, de la justicia. Ello abonará a crear una suerte de celo institucional democrático cuya afinidad por el humanismo y lo que ello implica, será en beneficio de la sociedad y en favor de los intereses de la patria; para ello es indispensable que esos valores sean un fundamento real, aplicable y aplicado en la política. Todo esto será, en última instancia, una manera de que el Estado y sus componentes sean cada más democráticos.

Los valores democráticos, como todos los valores y los principios éticos y morales, deben ser ejercidos, practicados y difundidos, pero también tienen que ser defendidos de aquellos que los niegan o que les restan importancia, ya sea que lo hagan con sus expresiones e ideología o que se refleje en sus actos como una consecuencia de las conductas capitalistas en las que lo más importante es el beneficio inmediato sin importar el perjuicio 
causado a los demás. No debemos renunciar a esos valores y principios ni permitir que se haga apología de su renuncia, al contrario, debemos remover los obstáculos que nos impiden ejercerlos.

\section{LA DEMOCRACIA Y LA FRATERNIDAD}

En México, el artículo tercero de la Constitución Política establece el derecho a la educación y en su fracción II, inciso a), establece que el criterio orientador de la educación "Será democrático, considerando a la democracia no solamente como una estructura jurídica y un régimen político, sino como un sistema de vida fundado en el constante mejoramiento económico, social y cultural del pueblo..." (CPEUM, 2019), esto alude a la manera en la que se debe considerar el concepto "democracia", y distingue con toda precisión dos posturas: una en la que refiere al sistema jurídico que otorga los lineamientos básicos para el funcionamiento del Estado yal sistema político que prevélas condiciones generales por las que las personas pueden acceder al poder público y otra en la que alude a un sistema de vida. Significa que no solamente se debe aplicar en cuanto a situaciones o circunstancias relativas a lo político o a lo jurídico, sino que, de acuerdo con la definición constitucional, va más allá: tiene aplicabilidad en todo aquello en lo que el ciudadano tenga contacto, con toda aquella circunstancia en la que la actividad de las personas tenga una injerencia, ahí donde el ser humano tenga una relación y un contacto con otro ser humano, habrá democracia y, por supuesto, sus valores inherentes a la misma. Es decir, la democracia más que una forma de gobierno y un instrumento para la toma de decisiones en la vida pública de un Estado, es una manera de vivir la vida, lo cual implica que sus características (valores y principios) no solamente deben estar presentes en la actividad estatal o gubernamental (por ejemplo, para la renovación de cargos públicos en el gobierno), sino que también debe permear en toda la conducta y actividad cotidiana de las personas, sin que necesariamente sea una condición sine qua non el hecho de que esas personas o ciudadanos detenten algún cargo público. Consecuente con lo anterior, si consideramos que el ciudadano es aquel sujeto cuya conducta cotidiana social debe estar influida por esos principios democráticos, y si tenemos en cuenta que todos los gobernantes, detentadores del poder público, funcionarios y servidores públicos y estatales, así como agrupaciones y partidos políticos (finalmente también conformados por personas), son ciudadanos (con los derechos y obligaciones políticos inherentes a esa cualidad), entonces también -y con mayor razón- deben estar presentes las características democráticas en todo su actuar. Ese mismo precepto, en su fracción II, inciso c), establece que la educación

Contribuirá a la mejor convivencia humana, a fin de fortalecer el aprecio y respeto por la naturaleza, la diversidad cultural, la dignidad de la persona, la integridad de las familias, la convicción del interés general de la sociedad, los ideales de fraternidad e igualdad de derechos de todos, evitando los privilegios de razas, de religión, de grupos, de sexos o de individuos. (CPEUM, 2019)

"Convivir" significa vivir en compañía de otro o de otros y alude a una coexistencia de las personas, a una necesaria compatibilidad y comprensión de los seres humanos por los demás seres humanos. Mejorar la convivencia humana implica que las personas refuercen esas ligas de compatibilidad y mejoren las posturas de comprensión que son necesarias para poder existir unos con otros. En una sociedad es ineludible convivir con los demás integrantes de esa misma sociedad, por lo que todo aquello que atente a la mejor forma de relacionarse entre ellas mutila la fraternidad y todo lo que la ayude es en realidad una circunstancia más democrática. No se puede mejorar la convivencia sino aplicando otros valores o principios (que también lo son de la democracia), como el respeto por el otro, la tolerancia, etc., todo lo cual lleva a una interacción pacífica entre los seres humanos que integran la sociedad. El "aprecio" implica una estimación afectuosa hacia alguien. Significa aumentar el precio o aumentar el valor de algo o de alguien, pero, 
sobre todo, reconocer y estimar el valor de algo o de alguien a través de sus méritos. No se puede concretar sin que haya de por medio una sensación de afecto o de estima hacia esa cosa o persona. Para lo anterior es necesario que se perciban los méritos de las personas para poderlos estimar, para que sea posible apreciarlos, y esto no se logra sin que se preste la debida atención a la persona cuyos méritos se pretende que sean apreciados. El "respeto" es la consideración o la deferencia que se tiene hacia las demás personas, implica una atención dada a los otros, que no solamente sean personas cuyo actuar sea omitido o ignorado, sino que sean atendidos y tomados en cuenta con relación a lo valioso que pudiera ser su participación o sus acciones. Un poco de cortesía podría ser benéfico, siempre que no se comprometa la necesaria rigurosidad en cuanto a la legalidad o en relación con el respeto a la normatividad jurídica. La "dignidad de la persona” significa que dicha persona es merecedora de algo y ese algo es o debe ser proporcional al mérito de sus acciones. El "interés general de la sociedad" es algo que a la mayoría de los integrantes de la sociedad les puede servir, se trata de acciones o conductas de los integrantes de la sociedad que son útiles a la misma sociedad en su mayor parte. Cuando algo se realiza en interés general de la sociedad significa que hay una ganancia o un valor para la misma sociedad y no, por el contrario, que la sociedad $-\mathrm{y}$ sus integrantes- tengan que remediar los daños o pagar las deficiencias de acciones o conductas que no están dirigidas a ese interés general. Para que este aspecto pueda ser desarrollado, no basta con que los ciudadanos o los integrantes de una sociedad dirijan sus conductas para su beneficio particular (lo cual, prima facie, podría ser considerado como un requisito inicial para que una sociedad funcione y, sobre todo, para que progrese), sino que también es necesario que en la conducta de las personas haya una especial y particular inclinación anímica hacia la utilidad, provecho o ganancia (en general un beneficio) de la sociedad y/o de la mayoría (o de muchos) de sus integrantes. El efecto que debe tener la existencia del interés general de la sociedad es que se produzca una nueva situación de las personas o de la mayoría de las personas (de la sociedad en general), que sea conveniente o benéfica, ya sea desde el punto de vista moral o desde la perspectiva de lo material.

Además de la Constitución Política, existen otras leyes reglamentarias que de manera congruente regulan a la educación y prevén que haya democracia en la misma, haciendo énfasis en el valor de la fraternidad (aunque en ocasiones esto no se haga de manera expresa), por ejemplo, la Ley General de Educación en su artículo 16 dice que "La educación (...) luchará contra (...) las servidumbres, los fanatismos, los prejuicios, la formación de estereotipos, la discriminación y la violencia...” (LGE, 2019), lo que ya de entrada está ligado a las ideas de fraternidad, ya que la idea de "luchar contra las servidumbres" implica evitar que haya sujeciones agravadasu obligacionesinexcusables nolegalespara hacer algo, pero tal sujeción podría estar también causada por ciertas circunstancias que coartan la libertad (otro de los valores de la democracia). La idea de "luchar contra los fanatismos" significa rechazar un apasionamiento desmedido en defender creencias u opiniones de carácter político, cuando no hay fundamento científico para ello. "Luchar contra los prejuicios" es evitar que las personas prejuzguen, que no haya calificaciones y opiniones -desfavorables o no- acerca de algo que no se conoce a cabalidad. "Luchar contra la formación de estereotipos" implica no incurrir en la aceptación de una ideología simplemente por ser aceptada de forma inmodificable en un grupo o sociedad. "Luchar contra la discriminación” es no otorgar un trato desigual a una persona o a un grupo de personas por motivos raciales, religiosos, políticos, sexuales, etc. Finalmente, "luchar contra la violencia" significa impedir que se haga uso de la fuerza (ya sea física o moral) contra la voluntad de las demás personas, con la finalidad de infringir lo establecido jurídicamente. Además de lo anterior, ese precepto establece que la educación responderá a determinados criterios, y el primero de ellos es, precisamente, la democracia, y la define -en su fracción I- de la misma manera que lo hace la Constitución Política, mientras que en la

Pensamiento Americano Vol. 14 - No. 27 - p.p. 39-56 • 2021 • Enero - Junio • Corporación Universitaria Americana • Barranquilla, Colombia • ISSN-e: 2745-1402 http://publicaciones.americana.edu.co/index.php/pensamientoamericano/index 
fracción III se amplía el catálogo criterial por el cual se rige la educación: "Será humanista, al fomentar el aprecio y respeto por la dignidad de las personas, sustentado en los ideales de fraternidad e igualdad de derechos, promoviendo el mejoramiento de la convivencia humana y evitando cualquier tipo de privilegio de razas, religión, grupos, sexo o de personas...” (LGE, 2019).

En esa porción normativa podemos observar la existencia de un concepto adicional a los que ya se habían establecido, el "humanismo", el cual refiere a todo aquello que esté relacionado con el ser humano, con su desarrollo en el mundo y en la sociedad y con todo aquello con lo que tenga contacto y sea producto de su actividad. El humanismo implica el conocimiento de lo humano, pero no solamente eso, sino que también obliga a cultivar lo humano, o sea, todo lo que sirve y beneficia al ser humano, todo lo que le ayuda a ser, a desarrollarse y a producirse. El humanismo obliga a restaurar los valores y a evitar su demérito e inobservancia. Debe mediar un interés por parte del ser humano y no solamente quedar como una necesidad social, con la finalidad de que el hombre siga siendo el centro de atención benéfica para el mismo hombre. En la fracción IV del mismo artículo se continua en un sentido similar al prever que se "Promoverá el respeto al interés general de la sociedad, por encima de intereses particulares o de grupo, así como el respeto a las familias, a efecto de que se reconozca su importancia como los núcleos básicos de la sociedad y constituirse como espacios libres de cualquier tipo de violencia...” (LGE, 2019), y por último, en el artículo 30, fracción XVIII, de esa misma codificación jurídica, se hace referencia a que en los contenidos de los planes y programas de estudio se incluirá "El fomento de los valores y principios del cooperativismo que propicien la construcción de relaciones, solidarias y fraternas...” (LGE, 2019).

El "cooperativismo" entendido como aquella tendencia a la práctica de los regímenes de cooperación que, aunque está más referido a situaciones económicas, en este caso lo importante es además el aspecto social. Asimismo, el artículo
6 de la Ley Reglamentaria del artículo $3^{\circ}$ de la Constitución Política establece los principios del sistema educativo mexicano y de lo más importante y relacionado con el tema que ocupa el presente trabajoestá el mandatodeque exista “....concordancia con el enfoque de derechos humanos, de igualdad sustantiva y de respeto irrestricto a la dignidad de las personas...” (LRA3CPEUM, 2019). Todos esas ideas derivadas del concepto de "fraternidad", aunado al hartazgo ciudadano en México (derivado de muchos fenómenos de inseguridad, fraudes, agresiones, violaciones a derechos humanos, y un largo etcétera), nos hacen concluir que la fraternidad ha sido un concepto que, si bien está referido (aunque no expresamente codificado) en la Constitución y en la legislación mexicanas, no ha sido debidamente observado ni aplicado en la realidad política, lo cual va en detrimento de la forma de gobierno democrática. Lo anterior aplica también para algunos otros estados democráticos, ya que ese valor es un aspecto distintivo de la democracia que pretenden implementar y sostener en sus respectivas sociedades. $\mathrm{Al}$ no ser el propósito principal de este trabajo, solamente mencionaré como ejemplo de lo anterior a la Constitución francesa, que en la parte final de su preámbulo se pude leer lo siguiente:

En virtud de estos principios [se refiere a los derechos humanos y a la soberanía nacional] y del de la libre determinación de los pueblos, la República ofrece a los Territorios de Ultramar que manifiesten la voluntad de adherirse a ella nuevas instituciones fundadas en el ideal común de libertad, igualdad y fraternidad y concebidas para fortalecer su evolución democrática. (CF, 2008)

Asimismo, en el artículo 2, correspondiente al título primero "De la soberanía”, dice, entre otras, que "El lema de la República es 'Libertad, Igualdad, Fraternidad'...”; y en el artículo 72-3 establece que "La República reconoce a las poblaciones de Ultramar dentro del pueblo francés, compartiendo un ideal común de libertad, igualdad y fraternidad..." (CF, 2008). 
Ahora bien, de acuerdo con el diccionario de la lengua, "fraternidad" es la amistad o afecto entre hermanos o entre quienes se tratan como tales (RAE, 2019). También significa "hermandad", lo cual refiere a la relación de parentesco entre hermanos, amistad íntima o unión de voluntades, correspondencia que guardan varias cosas entre sí, liga, alianza, o confederación entre varias personas, gente aliada o confederada (RAE, 2019). Intervienen conceptos como "respeto", "dignidad", "igualdad", "solidaridad", de ahí que la fraternidad se debe considerar como un valor universal y no como una característica localizada o particularizada, de tal manera que sus efectos deben permear en toda la actuación y conducta de los seres humanos, y al decir esto se incluye, desde luego, la actividad política y toda aquella relacionada con y derivada de la función pública de quienes detentan el poder público. Así, la fraternidad obliga también a los políticos y gobernantes a ser solidarios, respetuosos y, de paso, empáticos con todas las demás personas. Tal vez la empatía es por donde deberíamos empezar todos los seres humanos, ya que al tener un sentimiento de identificación con las demás personas sería muy difícil no pensar en sus problemas y necesidades y, por ende, sería poco probable no ocuparse de ellas. Tal vez lo que se necesita es generar o practicar la capacidad de identificarnos con los demás para comprender sus necesidades y, a partir de ahí, poder llevar a cabo conductas destinadas a la solución de los problemas del otro o, al menos, que las conductas no sean realizadas con la finalidad de perjudicar o, en un extremo, de aumentar su desgracia.

Por ello, los otros dos valores de la democracia (libertad e igualdad) no se contraponen con el de fraternidad, antes bien, se complementan y se hacen congruentes unos con el otro, ya que algunos de los conceptos que son parte integral de la fraternidad inciden en algunos otros que son análogos en la libertad e igualdad, como el "respeto" y la "dignidad". En realidad, el valor "fraternidad" no se pierde ni se confunde en una maraña de conceptos morales o incluso religiosos, sino que se refuerzan unos con otros, antes bien, el problema es que en la realidad política y social mexicana no ha habido la aplicación adecuada y deseable de dicho valor, pues ha sido casi menospreciada incluso desde sus orígenes como precepto moral y como lema revolucionario, no obstante que en tiempos modernos ha sido muy utilizado, tal vez con fines más propagandísticos o mediáticos que prácticos y realistas.

Lo anterior ha tenido un efecto agudo en la sociedadquehaprovocadola omisión en laaplicación de valores como la honestidad, la solidaridad, la compasión, la justicia, responsabilidad, bondad, respeto, lealtad, sinceridad, amor, discreción, dignidad, altruismo, modestia, etc. Sin embargo, haciendo de lado esas intenciones demagógicas de incluir en los discursos oficiales a la fraternidad, se debe rescatar la verdadera esencia de su contenido ideológico, ya que incide en aquellos ideales contenidos también en los otros valores de la democracia (como la libertad, la igualdad e incluso la justicia). La intención que legítimamente tiene la fraternidad es la de sensibilizar y humanizar cada vez más a la humanidad, aunque esto suene a lugar común (o incluso a discurso oficial, una vez más), acerca de los otros valores y derechos fundamentales de las personas, sin los cuales no es posible (o se hace muy complicado) sostener una sociedad. La democracia (y sus componentes característicos incluidos) se puede considerar desde dos puntos de vista: el eminentemente teórico y el práctico. En ocasiones las posturas teóricas pueden llegar a ser demasiado utópicas por la separación que sus definiciones pueden representar respecto a su aplicabilidad en la realidad social, pero esto no debe significar que el contenido conceptual del concepto en cuestión deba cambiar para adaptarse a esa realidad, sino que la realidad debe ser la que se adapte al contenido del concepto. De lo contrario estaríamos ante una situación en la que los conceptos e ideas que deben sostener a un Estado dejan de ser sustento para modificarse y adecuarse a un sistema y a una práctica que podrían ser corruptos. Por ello resulta importante revisar hasta dónde la fraternidad puede ser considerada como parte integrante (específicamente como 
valor) de la democracia, o si solamente forma parte de un discurso elegante acuñado con la finalidad de impactar de forma mediática. Lo anterior en virtud de que los acontecimientos políticos que son producto de la acción de quienes detentan el poder político nos hacen dudar de que la fraternidad sea un axioma que verdaderamente se aplique en la actividad política (y en general en la social).

La relación existente entre los conceptos “democracia” y "fraternidad”, más allá de la obvia existente y derivada de que ésta es un valor de aquella (es decir, de que la "fraternidad" es una especie del género "democracia”), se da en virtud de que ambos conceptos apelan a ideas de libertad e igualdad, ya que, por ejemplo, no se puede ser democrático sin ser libres e igualitarios o sin proteger esas condiciones y no se puede ser fraterno sin proteger, respetar y practicar la libertad y la igualdad. El concepto "fraternidad", en su esencia, contiene a su vez otros conceptos para salvaguardar la convivencia, la inclusión, el diálogo, el respeto al otro, etc., todos ellos aspectos que tienden hacia la protección y práctica de las libertades y de la igualdad. Tal vez el significado más importante de la fraternidad sea el de que las personas no queramos tener mayores ventajas a menos que tales ventajas representen un beneficio real para aquellas personas que se encuentran en una peor situación. Maximizar la suma de beneficios es una actitud que se alienta con las políticas capitalistas y neoliberales, mientras que con la fraternidad (y con la democracia) las personas no desean beneficiarse de manera ventajosa a menos que tal beneficio promueva el interés de las demás personas; en contraste, las personas cuya actuación está basada en el capitalismo y en las políticas neoliberales lo que pretenden es precisamente lo contrario: obtener un beneficio ventajoso aún a costa del interés de las demás personas.

Si consideramos a la solidaridad como una adhesión de las personas a las causas o circunstancias de otras personas, entonces debemos considerar el impacto moral que esto representa, de tal manera que algunos de los postulados sobre la justicia social tienen aplicación, ya que existe cierta responsabilidad de los seres humanos respecto a los demás (siempre que existan ciertas condiciones), todo lo cual implica un cierto grado de práctica solidaria (Rawls, 2004); por tanto, con la fraternidad (y también con la solidaridad y, en general, con la justicia social) aquellas personas que se encuentran en una mejor circunstancia política, social, económica, etc., están en la disposición de aprovechar esa situación para obtener mayores ventajas siempre que su conducta represente un beneficio de los menos agraciados, mientras que con el capitalismo y las políticas neoliberales es todo lo contrario: entre más privilegiada sea la posición y las circunstancias de las personas, la única disposición que tienen es para aprovechar esas ventajas y poder acrecentar y mejorar esa situación privilegiada sin importar que las acciones derivadas de ello sean en perjuicio de los menos afortunados:

...la revolución industrial y el vigoroso desarrollo de la cultura económica capitalista que la siguió trajo consigo la progresiva disolución del antiguo "demos" preindustrial, y a cambio, el crecimiento exponencial de uno de sus componentes: los trabajadores urbanos asalariados (los nuevos “esclavos a tiempo parcial”). La dinámica capitalista no sólo era acumulativa; era también expropiatoria: tendía a desposeer a millones y millones de personas de sus bases tradicionales de existencia social. (Domènech, 2013, p. 21)

Por otro lado, la democracia en su esencia tiene una implicación de competencia, de pugna y de choque entre dos o más posturas, entre ideologías varias que, por su misma naturaleza y por su origen dispar tienen como característica propia el establecimiento de ciertos límites y de ciertas divisiones entre tales posturas ideológicas, lo cual podría pensarse que va en detrimento de la idea esencial de la "fraternidad"; incluso, en una democracia se deben tener bien presentes los límites establecidos por la legalidad, y esto implica la prohibición de que las personas, las instituciones o los órganos de gobierno, los rebasen, ya que en 
caso de ocurrir así, se estaría ante una infracción a uno de los fundamentos de la propia democracia. Sin embargo, la fraternidad no debe significar la demolición de esas barreras o límites democráticos y legales, sino que debe implicar cierto grado de paz en la convivencia humana y en la democrática confrontación de las ideas que de esa convivencia surgen, lo cual puede ocurrir si todas las personas estuviéramos dispuestas a renunciar a cierto grado de lo que se considera una exigencia justa y estricta para ubicarnos en un ámbito de "fraternidad".

\section{LA POLÍTICA MEXICANA Y LA DEMOCRACIA}

En México, constitucionalmente el pueblo ejerce su soberanía por medio de los poderes de la Unión y por medio también de los poderes de los estados y de la Ciudad de México y establece que la renovación de los poderes legislativo y ejecutivo se realizará mediante elecciones libres, auténticas y periódicas para lo cual los partidos políticos tienen una importante participación, no obstante que no son el único medio para que un ciudadano pueda ser electo a ocupar un cargo de elección, sí constituye el más usual para la postulación de candidaturas. Así mismo, ese documento fundamental nos refiere de manera muy directa a la actividad política del ciudadano mexicano, tan es así que incluso su propia denominación es Constitución "política", y a lo largo de su texto se encuentran referencias sobre esta actividad humana relacionadas con diversos tópicos de la vida social del país. Solamente como ejemplo de lo anterior se pueden mencionar los siguientes (CPEUM, 2019): I. Las instituciones políticas y las formas internas de convivencia y organización política como uno de los elementos de los pueblos indígenas, así como los derechos político-electorales de sus ciudadanos y el respeto de la participación y representación política conforme sus tradiciones y normas internas, políticas sociales para protección de sus migrantes, (artículo $2^{\circ}$ ); II. Ideología basada no solamente en el régimen político sino como sistema de vida en términos de un parámetro de la democracia en la educación, la cual deberá ser tendiente a la independencia política, el establecimiento de políticas incluyentes y transversales, la especialización en política educativa de algunos funcionarios educativos y las políticas de inclusión y permanencia en la educación superior como una obligación de las autoridades federales y estatales (artículo $3^{\circ}$ ); III. Políticas públicas dirigidas a la niñez (artículo $4^{\circ}$ ); IV. La prohibición de renuncia, pérdida o menoscabo de derechos políticos o civiles en cuanto a los contratos de trabajo (artículo $5^{\circ}$ ); V. El carácter público de la información en posesión de los partidos políticos, para el ejercicio del derecho de acceso a la información (artículo $6^{\circ}$ ); VI. El derecho de petición que en materia política solamente podrán ejercerlo los ciudadanos de la república (artículo $8^{\circ}$ ); VII. El derecho de asociación o reunión que en materia política solamente podrán ejercerlo los ciudadanos de la república (artículo $9^{\circ}$ ); VIII. El asilo político (artículo 11); IX. Políticas públicas en materia de comisión y prevención de delitos (artículo 21); X. La prohibición del ejercicio de la libertad de culto con fines políticos (artículo 24). XI. La planeación del desarrollo nacional para la democratización política y para las políticas de desarrollo social (artículo 26); XII. La prohibición de que los extranjeros se inmiscuyan en los asuntos políticos del país (artículo 33); XIII. El derecho de solicitar el registro de candidaturas a cargos de elección popular que corresponde a los partidos políticos y a los ciudadanos de manera independiente y el derecho de estos últimos de tomar parte en los asuntos políticos del país (artículo 35); XIV. El carácter de entidades de interés público que tienen los partidos políticos, su finalidad de promover la participación del pueblo en la vida democrática, contribuir a la integración de los órganos de representación política y hacer posible el acceso de los ciudadanos al ejercicio del poder público, la prohibición de calumniar a las personas por medio de la propaganda política, un sistema de medios de impugnación para garantizar y proteger los derechos políticos de votar, ser votado y de asociación (artículo 41); XV. La procedencia del juicio político (artículo 109).

Pero no solamente la Constitución es el documento en el que se encuentra plasmada la

Pensamiento Americano Vol. 14 - No. 27 - p.p. 39-56 • 2021 • Enero - Junio • Corporación Universitaria Americana • Barranquilla, Colombia • ISSN-e: 2745-1402 
actividad política de los integrantes del Estado, ya que también la legislación secundaria hace referencia a este aspecto, por ejemplo, la Ley General de Partidos Políticos regula "Los lineamientos básicos para la integración de sus órganos directivos [se refiere a los partidos políticos], la postulación de sus candidatos, la conducción de sus actividades de forma democrática...” (LGPP, 2014), también dice que los partidos políticos tienen como fin “... promover la participación del pueblo en la vida democrática...” (LGPP, 2014, artículo 3, párrafo 1), que promoverán “... los valores cívicos y la cultura democrática entre niñas, niños y adolescentes...” (LGPP, 2014, artículo 3, párrafo 3), pero también en cuanto a las agrupaciones políticas dice que “... coadyuvan al desarrollo de la vida democrática y de la cultura política, así como a la creación de una opinión pública mejor informada...” (LGPP, 2014, artículo 20), también deben conducir sus actividades y ajustar su conducta “... a los principios del Estado democrático...” (LGPP, 2014, artículo 25), y en cuanto a su propaganda, deberá ser para difundir las “... campañas de consolidación democrática...” (LGPP, 2014, artículo 72, inciso e).

Como se puede apreciar, la legislación no prevé de manera directa a la fraternidad, tal vez porque se trate de un concepto que implica más una circunstancia de carácter moral (o hasta religioso) que de tipo legal, sin embargo, lo moral incide en lo jurídico dándole forma para su posterior aplicabilidad. Tal vez por esa razón la fraternidad como valor democrático ha quedado en desuso en un medio eminentemente jurídico y político, sin embargo, en esencia no debe dejarse de lado para practicar la política, ya que uno de los parámetros que debe cumplir el político es la ética:

¿Cómo debe ser el político? O mejor aún, ¿cómo se debe hacer política? Inicialmente se puede decir que la política se debe hacer con un apego irrestricto a la ética; que ésta debe ser su parámetro principal y que sus postulados mínimos deben ser respetados y ejercidos por quien haga política -es decir, por el político-. (Ordóñez, 2014, p. 69)
Sin embargo, la realidad política y social nos indica la existencia de una situación diferente, al considerar, por ejemplo, los fraudes que han ocurrido en el ejercicio del poder público en México; solamente como un ejemplo de esto, basta referenciar la llamada "Estafa Maestra", mediante la cual el gobierno federal usó 128 empresas fantasma para desviar recursos millonarios (Animal Político y Mexicanos Contra la Corrupción y la Impunidad, $\mathrm{s} / \mathrm{f}$ ), con esto queda claro que la actuación de quienes detentan el poder público en México no se ha ajustado a los parámetros de la fraternidad $y$, consecuentemente, no se ha cumplido lo que teórica, constitucional y legalmente se exige para que sea una verdadera democracia.

Es necesario que las actividades política y gubernamental se apeguen a los valores que la democracia pregona, sobre todo al de fraternidad. Es indispensable que la política en México sea vista como una oportunidad de ejercer esos principios y valores democráticos y poder ser fraternos con las demás personas. Es urgente que la política mexicana se vea animada por un sentimiento de disposición para hacer el bien a las demás personas y también para cumplir con el cometido primordial que tienen todos aquellos que detentan un cargo público: servir al pueblo. Para que esto sea una realidad, debe haber una correspondencia entre las finalidades moralmente buenas que el político plantea a la población y los medios que utiliza para lograr no solamente los de carácter público, sino también los personales que adolecen de una moralidad dudosa:

En la consecución de los fines que el político se plantea, fines que al menos en discurso concuerdan con la categoría de "buenos", existen muchos otros factores que constituyen un obstáculo para el logro de esas metas, los cuales pueden ser solventados haciendo uso de otros fines de menor rango o de menos importancia, pero con un contenido moralmente malo; con ello tenemos indefectiblemente una de las circunstancias que conllevan a que los medios no sean tan "bondadosos" como los propios 
fines que, incluso, legítimamente ha planteado el político a la población. (Ordóñez, 2014, p. 71)

El capitalismo es un sistema económico y político que se basa en la propiedad privada de los medios de producción y en el libre mercado que, en muchos sentidos, es incoherente y hasta contradictorio con algunos principios democráticos, por ejemplo, de aquellos que pregonan la igualdad de derechos $\mathrm{y}$, desde luego, la fraternidad. En la actualidad, las políticas neoliberales que obedecen esos intereses capitalistas han provocado un distanciamiento del sentido humanitario (y, por ende, fraterno) que debe tener el servicio público y el ejercicio de un cargo, tanto de elección popular como de asignación, de tal manera que no solamente ha influido en la economía global y local, sino que también ha afectado en la manera de actuar de las personas en general, pero más aún de los gobernantes en particular al volverlos más ambiciosos respecto al poder público y económico en detrimento del cumplimiento de su primordial y sustantiva función de servir al pueblo. Se ha llegado al extremo, incluso, de disfrazar de democráticas muchas acciones de quienes ejercen la política mexicana, que en realidad son actos encaminados a satisfacer esos intereses particulares de una clase privilegiada que quiere poseer aún más privilegios gracias a la desmedida ambición que esas políticas neoliberales y capitalistas provocan. Como decía Weber, viven de la política en lugar de vivir para la política (Weber, 2004). Las políticas neoliberales y capitalistas, por la esencia de su ideología, se alejan de los valores de la democracia, sobre todo de la fraternidad, más aún considerando que este último valor no ha sido tomado en cuenta como sí lo han sido la libertad y la igualdad. Se alejan también de las cuatro virtudes cardinales de las que hablaba Platón ya que en la política mexicana no se moderan los apetitos ni se reprime el uso excesivo de los sentidos, sujetándolos a la razón para procurar el bien de la sociedad y del Estado, antes bien, los alientan cada vez más a satisfacer esos vicios y, por consecuencia, a alejarse de la fraternidad y de todo lo que ella conlleva en perjuicio de lo que se debe hacer en favor de la sociedad. De ahí que haya dos caminos para que el político pueda acceder al poder público, uno de ellos apegado a los cánones de la moral (es decir, al valor de la fraternidad) y el otro alejado de ella:

Pero puesto que hay otros dos modos de llegar a príncipe que no se pueden atribuir enteramente a la fortuna o a la virtud, corresponde no pasarlos por alto, aunque sobre ellos se discurre con más detenimiento donde se trata de las repúblicas. Me refiero, primero, al caso en que se asciende al principado por un camino de perversidades y delitos; y después, al caso en que se llega a ser príncipe por el favor de los conciudadanos. (Maquiavelo, 1989, p. 14)

Existen dos maneras de concebir a la ética cuando de aplicarla a las acciones de los políticos se trata: 1) desde el punto de vista de la convicción y 2) desde la perspectiva de la responsabilidad (Weber, 2004, p. 67). De acuerdo con la ética de la convicción es necesario obrar bien pero se deja el resultado de ese "buen" obrar bajo la consideración de una entidad suprema, por lo que en caso de que las consecuencias de una acción resultan ser malas, aquel que la ejecutó no se siente responsable de ellas y piensa que otra entidad es la responsable, como la sociedad, el sistema, la suerte, etc., mientras que con la ética de la responsabilidad las personas deben obrar sin perder de vista las consecuencias esperadas como resultado de esa acción, por lo que son considerados todos los defectos propios y el sujeto ejecutante es consciente de que las personas no son, de manera predeterminada, buenas, por lo que las consecuencias de suacción que son razonablemente previsibles no pueden ser atribuidas a otras personas. De acuerdo con algunos autores, el lema de 1789 ("Libertad, igualdad, fraternidad") contenía una

...declaración esencial de una filosofía de vida (...) la felicidad es un derecho humano y la búsqueda de la felicidad es una tendencia humana universal (...) y para alcanzar la felicidad los seres humanos tienen que ser libres, iguales y fraternos. (Bauman, 2007)

Por lo que la felicidad, a pesar de que es una

Pensamiento Americano Vol. 14 - No. 27 - p.p. 39-56 • 2021 • Enero - Junio • Corporación Universitaria Americana • Barranquilla, Colombia • ISSN-e: 2745-1402 http://publicaciones.americana.edu.co/index.php/pensamientoamericano/index 
circunstancia eminentemente personal, está fuertemente ligada a la construcción de condiciones sociales favorables para su logropor parte de los mismos individuos que integran a la sociedad, por lo que la búsqueda de la felicidad, además de ser una actividad meramente particular, constituye también una serie de acciones que se deben verificar en el espacio público, ya que no es posible ser feliz de manera individual cuando la persona se encuentra inmersa en una sociedad infeliz (Bauman, 2007). De esta manera, hay inmersos otros conceptos que coadyuvan en el logro de esa felicidad, mismos que están muy relacionados con algunas actitudes personales ocurridas en la vida diaria de las personas, pero que inciden decisivamente en las relaciones interpersonales (ya sean entre ciudadanos o entre estos y políticos o gobernantes), como evitar la indiferencia y vencer la enemistad:

El llamado de la fraternidad no debe solamente superar la viscosidad y la impermeabilidad de la indiferencia. Debe vencer la enemistad (...) y el problema clave del cumplimiento de la humanidad es el de ampliar el "nosotros", de abrazar, en la relación matri-patriótica terrestre, cada "ego alter" y de reconocer en él un "alter ego", es decir, un hermano humano. (Morin y Kern, 1993, p. 178)

Se trata de vencer la indiferencia social que se ha producido por décadas de prácticas egoístas y capitalistas, para darle un sentidoy unajustificación a la verdadera actitud de responsabilidad y de fraternidad, por lo que esta última puede ser un valor positivo, pero también una categoría de convivencia indispensable para que funcione adecuadamente una sociedad inmersa en las políticas capitalistas. No obstante, hay quien considera que la fraternidad aplicada estrictamente rebasa los límites legales (y deseables) establecidos por la propia democracia y que solamente puede tener una aplicación útil cuando surgen casos extremos en los que la fraternidad es "... la última tabla de salvación de una situación de crisis social aguda o de conflicto político agudo..." (Orrego, 2007, pp. 133), ya que, dice, no se trata de

...algo que se perciba como una categoría política que haya de operar de manera continuada. Más bien parece que, superada la emergencia, se acaba otra vez la fraternidad. O quizá resurgen con más fuerza las fraternidades "enclaustradas" [se refiere a la fraternidad que efectivamente opera y debe operar al interior de núcleos sociales compactados, como la familia o los integrantes de un grupo social determinado, como un estado o una patria], y comienza nuevamente el aspecto agonal de la política. (Orrego, 2007, pp. 133)

Ahora bien, no se debe perder de vista que el conflicto es una circunstanciainherente ala democracia y también a la política, pero debe ser compatible con la fraternidad y no contrario a ella, es decir, debe desarrollarse al amparo de la fraternidad y no en contra de ella para evitar que la destruya o la nulifique. En ocasiones es mejor expresar de frente (y con cierto grado de conflictividad) las ideas y posturas personales y contrarias a las delos demás, que solamentelimitarnos a asentir todo el tiempo con la intención de no romper el "fraternal equilibrio". En ese aspecto agonal de la política va inmerso -ineludiblemente- el concepto de soberanía, ya que todo poder (incluido, desde luego, el público) implica la existencia de una tensión entre dos elementos, uno que actúa en determinado sentido y otro que resiste en el contrario, y tal situación ocurre en una democracia al momento de tomar una decisión por el principio de mayoría -que es uno de los principios democráticos y también un instrumento para la toma de decisiones-, ya que la mayoría actúa con su decisión en un sentido adverso a aquel en el que lo hacen las minorías. La soberanía ciudadana derivada de los ambientes democráticos que constituye la forma de legitimar la validez de las decisiones contrasta -por ejemplo- con el derecho de propiedad (y, concretamente, con el de propiedad privada), por lo que una práctica de la política con características fraternales puede resultar complejo, más aún en un medio capitalista-mercantilista en donde la búsqueda del beneficio personal se realiza en detrimento del beneficio de los demás y el goce de tales beneficios para unos se concreta sobre la disminución de los beneficios de otros, ya que en el mayor disfrute de la igualdad se agudizan las desigualdades del resto de las personas que

Pensamiento Americano Vol. 14 - No. 27 - p.p. 39-56 • 2021 • Enero - Junio • Corporación Universitaria Americana • Barranquilla, Colombia • ISSN-e: 2745-1402 http://publicaciones.americana.edu.co/index.php/pensamientoamericano/index 
no pueden o que no tienen los instrumentos para su -al menos- cabal disfrute; en consecuencia, en un intento por salvaguardar y garantizar la unidad que implica la fraternidad, se excluyen a aquellos que no pertenecen al seno de la sociedad que la proclama. He ahí otra circunstancia agonal y antagónica, ya que las relaciones interpersonales (interciudadanas e interciudadanogobernante) se sostienen en algunas ocasiones por el respeto y garantía de la individualidad e independencia y en otras por la estrechez del vínculo administrativo generado por un gobierno paternalista y garantizador:

Las modificaciones en los distintos subsistemas, su diferenciación y autonomización, nos hablan a veces de anomia, de una fragilización de los lazos de relación mutua, de una falta de referentes. El individuo parece vivir esta situación de manera paradojal: por un lado, parece celebrar la conquista de espacios de independencia y autodeterminación; por el otro, parece necesitar -para sostener esa misma libertad-, aseguramientos, certidumbres, vinculaciones al menos como horizontes potenciales, frente al sufrimiento, la falta de trabajo, la violencia o la falta de sentido. (Salvat, 2007,pp.133-157)

El problema surge cuando ese gobierno interventor necesita hacer un uso más desmedido y atípico del poder que goza para tener la posibilidad de cumplir con la protección paternalista que el ciudadano exige, pero en contradicción a la individualidad e independencia que en otras ocasiones requiere (o tal vez no sea en razón del momento en el que esto ocurre, sino de a quien se le aplica o, incluso, una combinación de ambas razones), lo que genera una incongruencia insalvable derivada de la tensión entre esa individualidad y la corresponsabilidad de protección mutua que tienen todos los ciudadanos:

¿Cómo podría cada uno sentirse entonces hermano del otro también en el espacio público una vez que se van consolidando las tendencias descritas más arriba? ¿Frater, es decir, corresponsable de su situación y de la de cada quién más allá de sí? ¿Cómo sería ello posible si tenemos cada vez más individuos (noconfundirconpersonaosujeto),ycadavezmenos sociedad? Esta temática de la corresponsabilidad por la suerte del otro ha sido históricamente puesta al día mediante las consecuencias que se siguen de la violación sistemática de los derechos humanos. (Salvat, 2007,pp.133-157)

Por ello, para que la fraternidad pueda ser cabalmente practicada como valor democrático en la política mexicana se requiere, más que de estructuras políticas e institucionales, de una ideología en la que esas dos situaciones de la sociedad (individualidad y corresponsabilidad) puedan conciliarse en unambiente en el que ciudadanos y gobernantes estén inmersos en unmediosocialy, en consecuencia, estén conscientes de ello. Que cuando emerja la necesaria enemistad política no lo sea con cualidades derivadas de la ambición sino de la necesidad de mejorar el entorno social por medio de la discusión generadora de nuevas ideas que a su vez da la posibilidad de tomar decisiones públicas, de tal suerte que los límites infranqueables en una discusión o en el ejercicio de la política sean muy claros, estén bien definidos y se pueda hablar de una enemistad política necesaria y de una fraternidad como una categoría no solamente de la democracia, sino también de la res publica. Esto también sería un impulso para que el concepto de fraternidad no sea de aplicación momentánea ni obedeciendo a intereses individuales y para evitar su práctica en solo situaciones límite y alentándola en las ordinarias, de tal manera que habría una fraternidad como valor democrático en la política mexicana actuando constitucional y legalmente, pero, además en el nivel moral en todo el actuar tanto de la población como de los gobernantes.

\section{CONCLUSIÓN.}

El concepto de democracia en la regulación constitucional mexicana adopta dos posturas, una relativa al sistema jurídico y la otra como un sistema de vida. Este último es en cuanto a la aplicabilidad en todo aquello en lo que el ciudadano tenga contacto, en toda circunstancia en la que la actividad de las personas tenga una injerencia, en donde el ser humano esté relacionado con otro ser humano y tenga la necesidad de interactuar, lo que en general se produce al estar

Pensamiento Americano Vol. 14 - No. 27 - p.p. 39-56 • 2021 • Enero - Junio • Corporación Universitaria Americana • Barranquilla, Colombia • ISSN-e: 2745-1402 http://publicaciones.americana.edu.co/index.php/pensamientoamericano/index 
insertos en una sociedad. No se debe omitir que todos los gobernantes y todas aquellas personas que detentan o que ejercen un cargo público, ya sea por designación o por elección, son primeramente ciudadanos con todo lo que el concepto de ciudadano implica (derechos y obligaciones políticos inherentes a esa cualidad). En la regulación jurídica secundaria, la fraternidad no cuenta conunacodificación expresa,sinembargo,losconceptos encontrados la refieren directamente, por ejemplo, libertad, igualdad, respeto en general y también por el otro,aprecio, dignidad delapersona,interés generaldela sociedad, ubicarse por encima de intereses particulares o de grupo, convivir, luchar contra las servidumbres, los fanatismos, los prejuicios, también contra la formación de estereotipos, la discriminación, la violencia, lo que conlleva un humanismo, cooperativismo, solidaridad, empatía y, finalmente, derechos humanos. A pesar de que el concepto de "fraternidad" no tuvo un adecuado desarrollo por diversas circunstancias tanto doctrinarias como de carácter político, lo cierto es que, en esencia, tiene incluso una mayor importancia que los otros dos conceptos que integran la tríada de valores democráticos, es decir, la libertad y la igualdad, ya que están inmersos en aquel. Más allá del nivel jurídico, es importante el aspecto ético y moral, por lo que hace falta también desarrollar la capacidad de ponerse en el lugar del otro para evitar el individualismo ambicioso y egoísta provocado por las políticas capitalistas y estimular la capacidad de que las personas evitemos el deseo de tener mayores ventajas, a menos que tales ventajas representen un beneficio en términos reales a otras personas que se encuentran en una peor situación.

\section{Referencias}

Constitución Francesa de 4 de octubre de 1958 (CF). (2008). Recuperado el 18 de febrero de 2020 de https://www.senat.fr/ fileadmin/Fichiers/Images/lng/constitution-espagnol_juillet2008.pdf

Constitución Política de los Estados Unidos Mexicanos (CPEUM). (2019). Recuperado el 2 de febrero de 2020 de http://www. diputados.gob.mx/LeyesBiblio/pdf/1_201219.pdf

Ley General de Educación (LGE). (2019). Recuperado el 2 de febrero de 2020 de http://www.diputados.gob.mx/LeyesBiblio/pdf/LGE_300919.pdf

Ley General de Partidos Políticos (LGPP). (2014). Recuperado el 2 de febrero de 2020 de http://www.diputados.gob.mx/LeyesBiblio/pdf/LGPP_130815.pdf

Ley Reglamentaria del Artículo $3^{\circ}$ de la Constitución Política de los Estados Unidos Mexicanos, en Materia de Mejora Continua de la Educación (LRA3CPEUM). (2019). Recuperado el 2 de febrero de 2020 de http://www.diputados.gob.mx/LeyesBiblio/pdf/LRArt3_MMCE_300919.pdf

Animal Político y Mexicanos Contra la Corrupción y la Impunidad. (s/f). La estafa maestra. Graduados en desaparecer dinero público. Recuperado el 7 de marzo de 2020 de https://www.animalpolitico.com/estafa-maestra/

Arista, L. (2019). \#PrimerInforme: La Guardia Nacional cumple dos meses y tiene escasos resultados”. Recuperado el 8 de septiembre de 2020 de https://politica.expansion.mx/mexico/2019/09/01/primerinforme-la-guardia-nacional-cumple-dos-meses-y-tiene-escasos-resultados

Article 19. (2018). Ante el silencio ni borrón ni cuenta nueva. Recuperado el 10 de septiembre de 2020 de https://articulo19.org/ wp-content/uploads/2019/05/Ante-el-Silencio-Ni-BorronNi-Cuenta-Nueva_ABRv2.pdf.

Bauman, Z. (2007). Liquid Identity en Architettura e política, organizada por el Politécnico di Milano, 22-23 de marzo.

Domènech, A. (2013). La metáfora de la fraternidad republica- 
no-democrática revolucionaria y su legado al socialismo contemporáneo. Revista de Estudios Sociales (no. 43), 14-23. https://journals.openedition.org/revestudsoc/7726

France Diplomatie (s/f). Libertad, Igualdad, Fraternidad. Recuperado el 18 de febrero de 2020 de https://www.diplomatie.gouv.fr/es/venir-a-francia/conozca-francia/simbolos-de-la-republica/article/libertad-igualdad-fraternidad

González Menéndez, R. (2005). Los valores morales. Revista Cubana de Salud Pública, vol. 31(núm. 4), 269-282. https:// www.redalyc.org/articulo.oa?id=21418845001

Heidelberg Institute for International Conflict Research (HIIK). (2019). Conflict Barometer 2018. Disputes. Non-violent crisis. Violent crisis. Limited wars. Wars, (no. 27), 100-101. https:// hiik.de/conflict-barometer/current-version/?lang=en

Instituto Nacional de Estadística y Geografía (ma). (2017). Seguridad pública y justicia. artículo 22. Recuperado el 15 de febrero de 2020 de https://www.inegi.org.mx/temas/incidencia/

Maquiavelo, N. (1989). El Príncipe. Editorial Porrúa.

Morin, E. y Anne Brigitte, K. (1993). Terre-Patrie. Editorial Nueva Visión.

Ordóñez, J. (2014). La ética de la responsabilidad y el coto vedado de la democracia como manifestación de los derechos humanos en la actividad política. Revista Dígnitas, año VIII(número 24), 51-74. https://www.codhem.org.mx/localuser/ codhem.org/difus/dignitas/dignitas24.pdf

Orrego, C. (2007). Comentarios a la ponencia principal en A. Baggio et. al. (ed), Libertad, igualdad, ¿́fraternidad? (volúmen 27, no. 1, pp. 133-157) Revista de ciencia política, recuperado el 22 de febrero de 2020 de https://scielo.conicyt.cl/scielo. php?script=sci_arttext\&pid=S0718-090X2007000200007

Rawls, J. (2004). Teoría de la justicia. Fondo de Cultura Económica.

Real Academia Española (RAE). (2019). Diccionario de la Lengua Española. Edición del Tricentenario”. https://dle.rae. es/?w=fraternidad
Salazar, L. y Woldenberg, J. (2012). Principios y valores de la democracia. Cuadernos de divulgación de la democracia. Instituto Federal Electoral, no. 1 .

Salvat, P. (2007). Comentarios a la ponencia principal en A. Baggio et. al. (ed), Libertad, igualdad, ¿ifraternidad? (volumen 27, no. 1,pp. 133-157) Revista de ciencia política, recuperado el 22 de febrero de 2020 de https://scielo.conicyt.cl/scielo.php?scrip$\mathrm{t}=$ sci_arttext\&pid=S0718-090X2007000200007

Weber, M. (2004). El político y el científico. Editorial Colofón. 